\title{
MPV17-related mitochondrial DNA maintenance defect: new cases and review of clinical, biochemical, and molecular aspects
}

Ayman W. El-Hattab ${ }^{1}$, Julia Wang ${ }^{2}$, Hongzheng Dai ${ }^{3}$, Mohammed Almannai ${ }^{3}$, Christian Staufner ${ }^{4}$, Majid Alfadhel ${ }^{5}$, Michael J. Gambello ${ }^{6}$, Pankaj Prasun ${ }^{7}$, Saleem Raza ${ }^{8}$, Hernando J. Lyons $^{8}$, Manal Afqi ${ }^{9}$, Mohammed A. M. Saleh ${ }^{9}$, Eissa A Faqeih ${ }^{9}$, Hamad I Alzaidan ${ }^{10}$, Abduljabbar Alshenqiti ${ }^{10}$, Leigh Anne Flore ${ }^{11}$, Jozef Hertecant ${ }^{1}$, Stephanie Sacharow ${ }^{12}$, Deborah S-Barbouth $^{13}$, Kei Murayama ${ }^{14}$, Amit A. Shah ${ }^{15}$, Henry Lin ${ }^{15}$, Lee-Jun C. Wong ${ }^{3}$

${ }^{1}$ Division of Clinical Genetics and Metabolic Disorders, Pediatric Department, Tawam Hospital, Al-Ain, United Arab Emirates

${ }^{2}$ Medical Scientist Training Program and Program in Developmental Biology, Baylor College of Medicine, Houston, TX, USA

${ }^{3}$ Department of Molecular and Human Genetics, Baylor College of Medicine, Houston, TX, USA

${ }^{4}$ Department of General Pediatrics, Division of Neuropediatrics and Metabolic Medicine, University Hospital Heidelberg, Heidelberg, Germany

${ }^{5}$ King Abdullah International Medical Research Centre, King Saud bin Abdulaziz University for Health Sciences, Division of Genetics, Department of Pediatrics, King Abdulaziz Medical City, Ministry of National Guard-Health Affairs (NGHA), Riyadh, Saudi Arabia

${ }^{6}$ Division of Medical Genetics, Department of Human Genetics, Emory University School of Medicine, Atlanta, GA, USA

${ }^{7}$ Department of Genetics and Genomic Sciences, Icahn School of Medicine at Mount Sinai, New York, NY, USA

${ }^{8}$ Department of Pediatrics, St John Hospital and Medical Center and Wayne State University School of Medicine, Detroit, Michigan, USA.

${ }^{9}$ Section of Medical Genetics, King Fahad Medical City, Children's Specialist Hospital, Riyadh, Saudi Arabia

${ }^{10}$ Department of Medical Genetics, King Faisal Specialist Hospital and Research Center, Riyadh, Saudi Arabia

${ }^{11}$ Division of Genetic, Genomic, and Metabolic Disorders, Children's Hospital of Michigan and Wayne State University, Detroit, MI, USA

${ }^{12}$ Division of Genetics and Genomics, Boston Children's Hospital, Boston, Massachusetts, USA

${ }^{13}$ Human Geneties, University of Miami, Coral Gables, FL, USA

${ }^{14}$ Department of Metabolism, Chiba Children's Hospital, Chiba, Japan

${ }^{15}$ Division of Gastroenterology, Hepatology, and Nutrition, Children's Hospital of Philadelphia, Philadelphia, PA,

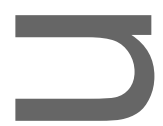

This is the ant manuscript accepted for publication and has undergone full peer review but has not been the wo tl copyediting, typesetting, pagination and proofreading process, which may lead to differences betw this version and the Version of Record. Please cite this article as doi: 10.1002/humu.23387. 


\section{Corresponding author:}

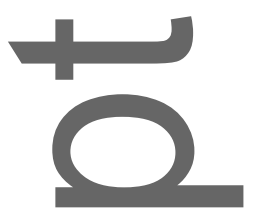

Abstract

Mitochondrial DNA (mtDNA) maintenance defects are a group of diseases caused by deficiency of proteins involved in mtDNA synthesis, mitochondrial nucleotide supply, or mitochondrial dynamics. One of the mtDNA maintenance proteins is MPV17 which is a mitochondrial inner membrane protein involved in importing deoxynucleotides into the mitochondria. In 2006, pathogenic variants in MPV17 were first reported to cause infantile-onset hepatocerebral mtDNA depletion syndrome and Navajo neurohepatopathy. To date, 75 individuals with MPV17-related mtDNA maintenance defect have been reported with 39 different MPV 17 pathogenic variants. In this report, we present an additional 25 affected individuals with 9 novel $M P V 17$ pathogenic variants. We summarize the clinical features of all 100 affected individuals and review the total 48 MPV17 pathogenic variants. The vast majority of affected individuals presented with an early-onset encephalohepatopathic disease characterized by hepatic and neurological manifestations, failure to thrive, lactic acidemia, and mtDNA depletion detected mainly in liver tissue. Rarely, MPV17 deficiency can cause a late-onset neuromyopathic disease characterized by myopathy and peripheral neuropathy with no or minimal liver involvement. Approximately half of the MPV17 pathogenic variants are missense. A genotype with biallelic missense variants, in particular homozygous p.R50Q, p.P98L, and p.R41Q, can carry a relatively better prognosis.

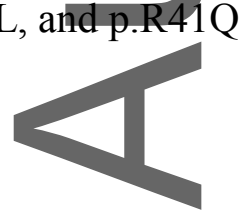

This article is protected by copyright. All rights reserved. 
Key words: MPV17, mitochondrial DNA (mtDNA), mtDNA depletion, multiple mtDNA deletions, mtDNA maintenance

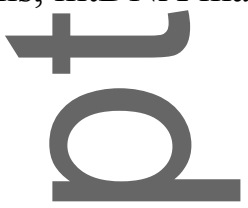

\section{Introduction}

Oven one thousand proteins are needed for the structure and function of normal mitochondria (Calvo et al., 2016). Mitochondria are under dual genome control with mitochondrial DNA (mtDNA) encoding a very small fraction of mitochondrial proteins, while the vast majority of mitochondrial proteins are encoded by nuclear DNA (nDNA). A human cell can contain several thousand copies of mtDNA distributed within hundreds of mitochondria (Lang et al., 1999). In contrast to nDNA, which replicates only during cell division, mtDNA synthesis is continuous throughout the cell cycle. Depending on the cell type, a certain copy number of mtDNA is required for the production of adequate mtDNA-encoded proteins. The maintenance of mtDNA depends on a number of nDNA-encoded proteins that function in mtDNA synthesis, maintenance of a balanced mitochondrial nucleotide pool, or mitochondrial dynamics. The mitochondrial nucleotide pool is maintained by a constant supply of nucleotides from mitochondrial salvage pathways and by import of cytosolic nucleotide into the mitochondrial matrix via specific transporters (El-Hattab and Scaglia, 2013; Spinazzola, 2011).

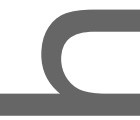

Defects in any of the proteins involved in mtDNA maintenance can result in impaired mtDNA synthesis leading to quantitative (mtDNA depletion) and qualitative (multiple mtDNA deletions) defeets in mtDNA. Defective mtDNA results in insufficient synthesis of the mtDNA-encoded mitochondrial proteins, leading to energy deficiency. Therefore, pathogenic

This article is protected by copyright. All rights reserved. 
variants in genes encoding these proteins cause mtDNA maintenance defects which are a group of diseases characterized by mtDNA depletion and/or multiple mtDNA deletions in affected organs (El-Hattab et al., 2017).

One of the mtDNA maintenance proteins is MPV17 which is a mitochondrial inner membrane protein that is believed to be involved in importing deoxynucleotides into the mitochondria. In 2006, pathogenic variants in MPV17 (MIM\# 137960) were first reported to cause a hepatocerebral mtDNA depletion syndrome of infantile onset that is characterized by hepatopathy and liver failure, developmental delay and other neurological manifestations, lactic acidosis, hypoglycemia, and mtDNA depletion in liver tissue (Spinazzola et al., 2006). Shortly after that, the homozygous pathogenic variant p.R50Q in MPV17 was found in children with infantile Navajo neurohepatopathy (NNH). $\mathrm{NNH}$ is an autosomal recessive disease prevalent among Navajo children in the southwestern United States and is characterized by hepatopathy, peripheral neuropathy, corneal anesthesia and scarring, cerebral leukoencephalopathy, failure to thrive, and metabolic acidosis (Karadimas et al., 2006). Because of the considerably phenotypic overlapping and being associated with defects in the same gene, both the MPV17-related heptaocerebral mtDNA depletion syndrome and the infantile NNH are considered to be allelic disorders being part of the same disease. Over the past decade many additional cases were published with the majority presenting with the infantile-onset hepatocerebral (encephalohepatopathic) disease; however, several reports presented individuals with later-onset disease that is associated with mild or no hepatic manifestations; expanding the phenotype associated with MPV17 pathogenic variants (Choi et al., 2015; Mendelsohn et al., 2014; Uusimaa et al., 2014). Furthermore, multiple mtDNA deletions inliver and muscle tissues have been described in few individuals with MPVI7 This article is protected by copyright. All rights reserved. 
pathogenic variants (Blakely et al., 2012; Garone et al., 2012; Piekutowska-Abramczuk et al., 2014). Because both mtDNA depletion and multiple mtDNA deletions can occur in association with MPV17 deficiency, calling this disease as "MPV17-related mtDNA maintenance defect" may more accurately describe the disease than the classic name of MPV17-related mtDNA depletion syndrome which indicates that MPV17 deficiency is only associated with mtDNA depletion (El-Hattab et al., 2017).

To date, 75 individuals with MPV17-related mtDNA maintenance defect have been reported with 39 different MPV17 pathogenic variants (Al-Hussaini et al., 2014; Al-Jasmi et al., 2011; A1Saman et al., 2012; Bijarnia-Mahay et al., 2014; Bitting and Hanson, 2016; Blakely et al., 2012; Choi et al., 2015; El-Hattab et al., 2010; Garone et al., 2012; Kaji et al., 2009; Karadimas et al., 2006; Kim et al., 2016; McKiernan et al., 2016; Mendelsohn et al., 2014; Merkle et al., 2012; Navarro-Sastre et al., 2008; Nogueira et al., 2012;

Piekutowska-Abramczuk et al., 2014; Sarkhy et al., 2014; Spinazzola et al., 2006, 2008; Uusimaa et al,2014; Vilarinho et al., 2014; Wong et al., 2007). In this report, we present additional 25 affected individuals and 9 novel MPV17 pathogenic variants. Herein, we review the clinical, biochemical, and molecular aspects of previously reported and new individuals with MPV17-related mtDNA maintenance defect.

\section{Methods}

Previously reported cases with MPV17-related mtDNA maintenance defect were identified through PubMed search. Baylor Genetics Laboratory databases were reviewed to identify cases with $M P V 17$ bilallelic pathogenic variants who have not yet been reported. Then, clinical, biochemical, and molecular data for these new cases were obtained from the treating

This article is protected by copyright. All rights reserved. 
physicians. The study was conducted according to Baylor College of Medicine (BCM) Institutional Review Board (IRB) approved protocols. Clinical data was obtained in a manner conforming with IRB ethical guidelines. The MPV17 reference sequence used is NM_002437.4. The DNA variant numbering system used is based on cDNA sequence.

Nucleotidenumbering uses +1 as the A of the ATG translation initiation codon in the reference sequence, with the initiation codon as codon 1 .

\section{MPV17 structure and function}

The MPKX 7 gene is located on chromosome 2p23-21 and contains eight exons. The MPV17 protein is composed of 176 amino acids and is localized in the inner mitochondrial membrane (Spinazzola et al., 2006). Molecular modeling of MPV17 predicted that this protein contains four transmembrane (TM) hydrophobic regions (TM1 from amino acid 18 to 38, TM2 from 53 to 73 , TM3 from 94 to 114, and TM4 from 131 to 151) with five hydrophilic regions including three short linker regions connect the TM spans and $\mathrm{C}$ - and $\mathrm{N}$ - terminus at the same side of the membrane. Although both $\mathrm{C}$ - and $\mathrm{N}$-terminals are located on the same side, it is unknown whether these terminal are facing the matrix side or the intermembrane space side (Wong et al., 2007) (Figure 1 and 2).

The exact function of MPV17 was unknown until a recent study showed that MPV17 loss causes mitochondrial deoxynucleotide insufficiency (Dalla Rosa et al., 2016). In Mpv17 deficient mice, liver mitochondria showed decreased mitochondrial deoxynucleotides and severe mtDNA depletion. Furthermore, elevated levels of replication intermediates indicated that the shortage of mitochondrial deoxynucleotides in the Mpv17 deficient mouse liver slows mtDNA replication. Study of fibroblasts obtained from individuals with MPV17 deficiency

This article is protected by copyright. All rights reserved. 
showed similar results with decreased mitochondrial deoxynucleotides and mtDNA depletion. Additionally, the mtDNA loss in these fibroblasts was prevented and rescued by deoxynucleoside supplementation (Dalla Rosa et al., 2016). This study established deoxynucleotide insufficiency in the mitochondria as the cause of mtDNA depletion in MPV17 deficiency (Dalla Rosa et al., 2016). Given that MPV17 localizes in the inner mitochondrial membrane, animal (mice and zebrafish) and yeasts studies showing that Mpv17 forms a channel allowing small molecules to pass (Löllgen and Weiher, 2015), and the finding of mitochondrial nucleotide insufficiency associated with its loss of function (Dalla Rosa et al., 2016) all support that MPV17 functions as an inner mitochondrial membrane channel importing cytosolic nucleotides into the mitochondria.

\section{MPV17 variants}

Molecular results for 73 of the 75 previously reported individuals with MPV17-related mtDNA maintenance defect were available and included 39 different pathogenic variants in the MPV17 gene. In this report we present 25 additional affected individuals and 9 novel pathogenic variants in $M P V 17$. Therefore, the total number of $M P V 17$ pathogenic variants known to date is 48 (Table and Figure 1). Novel pathogenic variants in this report have been submitted into LOVD (https://databases.lovd.nl/shared/screenings/MPV17). Approximately half of these variants are missense (22 out of $48 ; 46 \%$ ). Other types include nonsense ( 6 out of $48 ; 12 \%$ ), frameshift (6 out of 48; 12\%), splice-site ( 8 out of $48 ; 17 \%$ ), inframe deletions (4 out of 48 ; $8 \%$ ), and large exonic deletions ( 2 out of 48; 4\%). Aligning the 22 missense pathogenic variants along the protein domains showed some clustering of these variants ( 8 out of $22 ; 36 \%$ ) in a short 11 amino acid segment expanding from amino acid 88 to amino acid 98 and including

This article is protected by copyright. All rights reserved. 
the distal part of the second linker (connecting TM2 to TM3) and the proximal part of TM3

(Figure 2). The second linker is predicted to harbor a putative protein kinase $\mathrm{C}$ phosphorylation site, therefore this region may play an important role in the protein function (El-Hattab-et al., 2010; Wong et al., 2007).

The majority of the MPV17 pathogenic variants are exclusively occurring in one or a few families. However, the c.149G $>$ A (p.R50Q) has been reported in the homozygous status in several Navajo affected individuals. In addition, the c.278A $>$ C (p.Q93P) variant has been found in the homozygous status in multiple Arab families. Homozygous and heterozygous c.293C $>$ T (p.P98L) variant has been described in several affected individuals of various ethnicities (Table 1, Supp. Table S1, and Supp. Table S2).

Furthermore, we listed benign variants and variants of unknown significance in Supp. Table S3, which includes 94 variants.

\section{Clinical and biochemical features}

Including individuals in this report, clinical and biochemical features for 100 individuals with MPV17-related mtDNA maintenance defect are available. The vast majority of affected individuals ( 71 out of the 75 previously reported individuals and 25 out of the 25 individuals reported here) presented with an early-onset encephalohepatopathic (hepatocerebral) disease affecting mainly the nervous system and liver (Table 2). Four out of the 75 previously reported individuals presented with a neuromyopathic disease as discussed at the end of this section. MPV17-related encephalohepatopathy typically has an early onset during the neonatal period ( 36 out of $96 ; 38$ ) or infancy ( 56 out of $96 ; 58 \%$ ). Childhood onset

This article is protected by copyright. All rights reserved. 
(2-18 years) has been rarely reported (4 out of 96; 4\%) (Figure 3) (Table 2, Supp. Table S1, and Supp. Table S2).

All individuals with MPV17-related encephalohepatopathy present with hepatic and neurological manifestations. The universal finding is liver dysfunction that is described in all affected individuals and includes elevated transaminases, jaundice, and hyperbilirubinemia. In the majority of affected individuals ( 87 out of 96; 91\%) liver disease progresses to liver failure typically during infancy or early childhood. Other common hepatic manifestations include cholestasis (70 out of 96;73\%), hepatomegaly (60 out of 96; 63\%), and steatosis (49 out of 96; $51 \%$ ). Neurologically, affected individuals typically demonstrate developmental delay (75 out of $91 ; 82 \%$ ) and generalized hypotonia (67 out of $91 ; 74 \%)$. The majority of affected individuals have variable degrees of developmental delay. Some affected individuals present with psychomotor delays during early infancy while others have normal development early in life followed by loss of motor and cognitive abilities later in infancy or early childhood. The neurological manifestations can be overlooked or underestimated in these children with early onset of severe hepatic involvement. Failure to thrive is also common (82 out of $91 ; 90 \%$ ). Metabolic derangements occur in the majority of affected individuals and include lactic acidemia (72 out of 91; 79\%) and hypoglycemia (55 out of 91; 60\%). Hypoglycemia typically presents during the first six months of life and can be associated with lethargy, apnea, and/or seizures. Lactic acidosis is a biochemical finding with mild to moderate elevation of lactate (3-9 mmol/L) (E1-Hattab et al., 2012) (Table 2, Supp. Table S1, and Supp. Table S2). Less common manifestations that occur in less than half of the affected individuals include liver cirrhosis (20 out of 96;21\%), microcephaly (21 out of 91;23\%), motor and sensory peripheral neuropathy (17 out of $91 ; 19 \%$ ), and seizures ( 9 out of $91 ; 10 \%)$. About a

This article is protected by copyright. All rights reserved. 
third of affected individuals have feeding difficulties (28 out of $91 ; 31 \%$ ) and gastrointestinal dysmotility (30 out of 91; 33\%) manifesting as gastroesophageal reflux, recurrent vomiting, and diarrhea. Infrequent manifestations occurring in less than $10 \%$ of affected individuals are dystonia, ataxia, retinopathy, nystagmus, corneal anesthesia and ulcers, renal tubulopathy, nephrocalcinosis, and hypoparathyroidism. In addition, three affected individuals developed hepatocellutar darcinoma between ages 7 and 11 years (El-Hattab et al., 2010; Karadimas et al., 2006; Vilarinho et al., 2014) (Table 2, Supp. Table S1, and Supp. Table S2).

Brain magnetic resonance imaging (MRI) was performed in 71 individuals and showed abnormalities in less than half ( 31 out of $71 ; 44 \%$ ). The most common observed MRI abnormality is diffuse white matter abnormalities resembling leukodystrophy or hypomyelination $(27$ out of $71 ; 38 \%)$. Other infrequent findings include signal abnormalities in brainstem (6 out of $71 ; 8 \%$ ) and basal ganglia (6 out of 71; 8\%) (Merkle et al., 2012) (Table 2, Supp. Table S1, and Supp. Table S2).

All affeeted individuals tested for mtDNA content in liver show mtDNA depletion with mtDNA content ranging from $1-40 \%$ of tissue- and age-matched controls. The majority of affected individuals tested for mtDNA content in muscle tissue (16 out of $18 ; 89 \%$ ) had mtDNA depletion in muscles with mtDNA content ranging from $8-80 \%$ of tissue- and age-matched controls. However, two individuals reported to have normal mtDNA content in muscle (Piekutowska-Abramczuk et al., 2014; Uusimaa et al., 2014). MtDNA content in muscle tissue of affected individuals is typically higher than that in liver tissue. Interestingly, two children with MPV17-related encephalohepatopathy who died during infancy because of liver failure were found to have both mtDNA depletion and multiple mtDNA deletions in liver tissue (Piekutowska-Abramczuk et al., 2014). No other affected individuals with

This article is protected by copyright. All rights reserved. 
MPV17-related encephalohepatopathy have been tested for multiple mtDNA deletions, therefore, it is not known how common it is to have multiple mtDNA deletions in association with mtDNA depletion in this disease (Table 2, Supp. Table S1, and Supp. Table S2). MPV17-related encephalohepatopathy typically has a poor prognosis because in the majority of affected individuals, liver disease progress to liver failure typically during infancy or early chiłdhood. Liver transplantation has been performed for some affected individuals (17 out of $96 ; 18 \%)$. However, the outcome has not been satisfactory with more than half $(10$ out of 17; 59\%) of the transplanted children died during the post-transplantation period because of sepsis, respiratory failure, or multi-organ failure. The majority of affected children did not undergo liver transplantation (79 out of $96 ; 82 \%$ ). Among these individuals, $82 \%$ (65 out of 79 ) died because of liver failure. The majority died during infancy (52 out of $65 ; 80 \%$ ). Some died during early childhood ( $1-5$ years) (10 out of $65 ; 15 \%)$, adolescence ( 2 out of $65 ; 3 \%)$, and early adulthood ( 1 out of $65 ; 2 \%)$. Only 14 out 65 non-transplanted individuals (18\%) are reported alive with the oldest being 25 years old (Table 2, Supp. Table S1, and Supp. Table S2).

Another emerging rare phenotype associated with biallelic MPV17 pathogenic variants is a neuromyopathic disease that has been described in 4 out of $100(4 \%)$ individuals with MPV17-related mtDNA maintenance defects. This disease is of late onset and characterized by myopathy and neuropathy. One individual presented during childhood, two during adolescence, and one during adulthood (Figure 3). All the four individuals had myopathy and peripheral neuropathy. Liver manifestations were absent in two individuals while the other two had milder liver involvement but without liver failure. Development was normal in all affected individuals. One individual had ptosis and ophthalmoplegia. MtDNA was assessed in muscle This article is protected by copyright. All rights reserved. 
tissue in two individuals and showed normal mtDNA content with multiple mtDNA deletions

(Blakely et al., 2012; Choi et al., 2015; Garone et al., 2012) (Supp. Table S1).

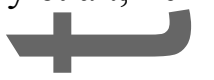

\section{Genotype-phenotype correlations}

MPV17-related mtDNA maintenance defect is typically associated with high mortality with 75 out of $100(75 \%)$ reported deceased. No clear genotype-phenotype correlation exists. However, a trend for a better survival can be observed in individuals with biallelic missense pathogenic variants compared to individuals with biallelic null (nonsense, frameshift, deletions, and splice-site) variants or compound heterozygous for missense and null variants. In individuals with null mutations $80 \%$ (41 out of 51) were reported deceased and the remaining $20 \%$ (20 out of 51 ) alive including only two adults. In comparison, in individuals with biallelic missense pathogenic variants $68 \%$ (32 out of $47 \%$ ) were reported deceased and $32 \%$ ( 15 out of 47 ) alive including 5 adults. Therefore, mortality could be slightly lower in association with biallelic missense pathogenic variants. Further evaluation of missense variants suggests that certain variants may carry a lower mortality and longer survival. Homozygous p.R50Q variant has been described in individuals of Navajo ancestry of whom $55 \%$ (6 out of 11) were reported deceased and 45\% (5 out of 11) living. In contrast to most cases of this disease where death occurs during infancy, 3 out of 6 died during adolescence or early adulthood (Bitting and Hanson, 2016; El-Hattab et al., 2010; Karadimas et al., 2006; Spinazzola et al.,2006). Similarly, homozygous p.P98L and homozygous p.R41Q variants each were reported in two individuals who were adults when reported (Blakely et al., 2012; Choi et al., 2015; Mendelsohn et al., 2014). These observations suggest that a genotype with biallelic missense variants, in particular homozygous p.R50Q, p.P98L, and p.R41Q, can carry

This article is protected by copyright. All rights reserved. 
a relatively better prognosis. The milder phenotype associated with the homozygous p.R50Q, p.P98L, and p.R41Q missense variants may suggest that amino acid substitutions at these positions result in a protein that preserves some residual function leading to a less severe

(1)

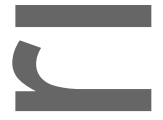

7. Management

There has been no curative treatment for this disease for which management remains largely symptomatic. Initially, affected individuals need to have a comprehensive evaluation to assess the degree of involvement of different organs, in particular liver and the nervous system. Hepatic evaluation includes liver function tests, ultrasound examination, alpha fetoprotein measurement, and consultation with a hepatologist. Neurological evaluation includes developmental and cognitive assessment, neurologic consultation and comprehensive neurologic examination, brain MRI, nerve conduction studies if neuropathy is suspected, and electroencephalogram (EEG) if seizures are suspected. In addition, affected individuals need ophthalmologic examination. Lactate and acid-base status should be monitored over time. Measuring blood glucose should be considered to monitor for hypoglycemia, particularly in the first 6 months of life. Management of this disease should involve a multidisciplinary team that aims to provide supportive care and symptomatic treatment for the complications associated with this disorder (El-Hattab et al., 2012, 2017).

Failure to thrive and feeding difficulties may require consultation with a gastroenterologist, nutritional support by an experienced dietitian, and the use of a nasogastric tube or gastrostomy tube feedings. Formulas enriched with medium-chain triglycerides can provide better nutritional support for children with cholestasis than formulas containing mainly This article is protected by copyright. All rights reserved. 
long-chain triglycerides. Avoidance of fasting by frequent or continuous feeding can be required to prevent hypoglycemia. In addition, the use of uncooked cornstarch can help in reducing symptomatic hypoglycemia in affected children. The use of cornstarch may also slow the progression of the liver disease (El-Hattab et al., 2017; Parini et al., 2009).

Although liver transplantation remains the only treatment option for liver failure in this disease, liyer transplantation in mitochondrial hepatopathies remains controversial, largely because of the multiorgan involvement in mitochondrial diseases (Parikh et al., 2016). Liver transplantation has been performed for $\sim 20 \%$ of affected children; however, the outcome has not been satisfactory with $\sim 60 \%$ of the transplanted children died during the post-transplantation period.

Although no curative therapy is currently available for this severe disease, our better understanding of the disease pathophysiology can open the door to evaluating novel potential therapeutic options. Studying mitochondria from Mpv17 deficient mice liver and fibroblasts obtained from individuals with MPV17 deficiency showed decreased mitochondrial nucleotides and severe mtDNA depletion. Interestingly, nucleoside supplementation to these fibroblast was able to prevent and rescue the mtDNA loss; therefore, nucleoside supplementation can be a potential therapeutic strategy for MPV17-related mtDNA maintenance defects (Dalla Rosa et al., 2016).

\section{Conclusions and summary}

Including individuals in this report, MPV17 deficiency causing MPV17-related mtDNA maintenance defect is described in 100 individuals. The vast majority (96\%) presented with early-onset encephalohepatopathic disease and small minority (4\%) presented with

This article is protected by copyright. All rights reserved. 
late-onset neuromyopathic disease. MPV17-related encephalohepatopathy typically has an early onset during neonatal period or infancy and is characterized by hepatic manifestations (liver dysfunction where the majority progress to failure, cholestasis, hepatomegaly, and steatosis), neurological manifestations (developmental delay and hypotonia), failure to thrive, lactic acidemia, and mtDNA depletion detected mainly in liver tissue. MPV17-related encephalohepatopathy typically has a poor prognosis with the majority of affected individuals dying during infancy or early childhood because of liver failure. MPV17-related neuromyopathy has later onset during childhood or adulthood and is characterized by myopathy, peripheral neuropathy, and no or minimal liver involvement. It is not fully understood why MPV17 deficiency affects specific organs, particularly liver and nervous system. The high expression of MPV17 in liver and brain (http://www.genecards.org/cgi-bin/carddisp.pl?gene=mpv17) could suggest a particular important function for MPV17 protein in these organs. It is also possible that there could be other proteins with high homology to MPV17 (Iida et al., 2003) that may play a protective role and could be expressed more abundantly in tissues where you do not typically see evidence of disease in MPV17 deficiency.

Approximately half of the MPV17 pathogenic variants are missense. Other types include nonsense, frameshift, splice-site, inframe deletions, and large exonic deletions. Some clustering of missense pathogenic variants is observed in a short 11 amino acid segment including the distal part of the second linker and the proximal part of TM3 suggesting an important role for this segment. A genotype with biallelic missense variants, in particular homozygous p.R50Q, p.P98L, and p.R41Q, can carry a relatively better prognosis.

This article is protected by copyright. All rights reserved. 
There has been no curative treatment for this disease for which management remains largely symptomatic. Liver transplantation has been performed for some affected children; however, the outcome has not been satisfactory with significant number of the transplanted children died during the post-transplantation period. Nucleoside supplementation can be a potential therapeutic strategy for MPV17-related mtDNA maintenance defects.

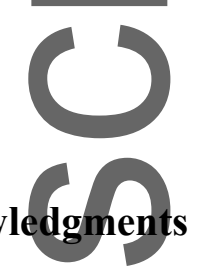

KM was supported by Practical Research Project for Rare/Intractable Diseases from AMED in Japan.

References

Al-Hussaini, A., Faqeih, E., El-Hattab, A.W., Alfadhel, M., Asery, A., Alsaleem, B., Bakhsh, E., Ali, A., Alasmari, A., Lone, K., Nahari, A., Eyaid, W., Al Balwi, M., Craig, K., Butterworth, A., He, L., Taylor, R.W., 2014. Clinical and molecular characteristics of mitochondrial DNA depletion syndrome associated with neonatal cholestasis and liver failure. J. Pediatr. 164, 553-559.e1-2. https://doi.org/10.1016/j.jpeds.2013.10.082

Al-Jasmi, E., Penefsky, H.S., Souid, A.-K., 2011. The phosphorescence oxygen analyzer as a screening tool for disorders with impaired lymphocyte bioenergetics. Mol. Genet. Metab. 104, 529-536. https://doi.org/10.1016/j.ymgme.2011.09.023

AlSaman, A., Tomoum, H., Invernizzi, F., Zeviani, M., 2012. Hepatocerebral form of mitochondrial DNA depletion syndrome due to mutation in MPV17 gene. Saudi J. Gastroenterol. Off. J. Saudi Gastroenterol. Assoc. 18, 285-289. https://doi.org/10.4103/1319-3767.98439

Bijarnia-Mahay, S., Mohan, N., Goyal, D., Verma, I.C., 2014. Mitochondrial DNA depletion syndrome causing liver failure. Indian Pediatr. 51, 666-668.

Bitting, C.P., Hanson, J.A., 2016. Navajo Neurohepatopathy : A Case Report and Literature Review Emphasizing Clinicopathologic Diagnosis. Acta Gastro-Enterol. Belg. 79, 463-469.

Blakely, E.L., Butterworth, A., Hadden, R.D.M., Bodi, I., He, L., McFarland, R., Taylor, R.W., 2012. MPV 17 mutation causes neuropathy and leukoencephalopathy with multiple mtDNA deletions in muscle. Neuromuscul. Disord. NMD 22, 587-591. https://doi.org/10.1016/j.nmd.2012.03.006

Calvo, S.E., Clauser, K.R., Mootha, V.K., 2016. MitoCarta2.0: an updated inventory of mammalian mitochondrial proteins. Nucleic Acids Res. 44, D1251-D1257. https://doi.org/10.1093/nar/gkv1003

Choi, Y.-R., Hong, Y.B., Jung, S.-C., Lee, J.H., Kim, Y.J., Park, H.J., Lee, J., Koo, H., Lee, J.-S., Jwa, D.H., Jung, N., Woo, S.-Y., Kim, S.-B., Chung, K.W., Choi, B.-O., 2015. A novel homozygous

This article is protected by copyright. All rights reserved. 
MPV17 mutation in two families with axonal sensorimotor polyneuropathy. BMC Neurol. 15, 179. https://doi.org/10.1186/s12883-015-0430-1

Dalla Rosa, I., Cámara, Y., Durigon, R., Moss, C.F., Vidoni, S., Akman, G., Hunt, L., Johnson, M.A., Grocott, S., Wang, L., Thorburn, D.R., Hirano, M., Poulton, J., Taylor, R.W., Elgar, G., Martí, R.,-Voshol, P., Holt, I.J., Spinazzola, A., 2016. MPV17 Loss Causes Deoxynucleotide Insuffieiency and Slow DNA Replication in Mitochondria. PLoS Genet. 12, e1005779. https://doi.org/10.1371/journal.pgen.1005779

El-Hattab, A.W., Craigen, W.J., Scaglia, F., 2017. Mitochondrial DNA maintenance defects. Biochim. Biophys. Acta 1863, 1539-1555. https://doi.org/10.1016/j.bbadis.2017.02.017

El-Hattab, A.W., Li, F.-Y., Schmitt, E., Zhang, S., Craigen, W.J., Wong, L.-J.C., 2010.

MPV 17-associated hepatocerebral mitochondrial DNA depletion syndrome: new patients and noyell mutations. Mol. Genet. Metab. 99, 300-308.

https://doi.org/10.1016/j.ymgme.2009.10.003

El-Hattab, A.W., Scaglia, F., 2013. Mitochondrial DNA depletion syndromes: review and updates of genetic basis, manifestations, and therapeutic options. Neurother. J. Am. Soc. Exp. Neurother. 10, 186-198. https://doi.org/10.1007/s13311-013-0177-6

El-Hattab, A.W., Scaglia, F., Craigen, W.J., Wong, L.-J.C., 2012. MPV17-Related Hepatocerebral Mitochondrial DNA Depletion Syndrome, in: Pagon, R.A., Adam, M.P., Ardinger, H.H., Wallace, S.E., Amemiya, A., Bean, L.J., Bird, T.D., Fong, C.-T., Mefford, H.C., Smith, R.J., Stephens, K. (Eds.), GeneReviews( $\left.{ }^{\circledR}\right)$. University of Washington, Seattle, Seattle (WA).

Garone, C., Rubio, J.C., Calvo, S.E., Naini, A., Tanji, K., Dimauro, S., Mootha, V.K., Hirano, M., 2012. MPV17 Mutations Causing Adult-Onset Multisystemic Disorder With Multiple Mitochondrial DNA Deletions. Arch. Neurol. 69, 1648-1651. https://doi.org/10.1001/archneurol.2012.405

Iida, R., Yasuda, T. Tsubota, E., Takatsuka, H., Masuyama, M., Matsuki, T., Kishi, K., 2003. M-LP, Mpv17-like protein, has a peroxisomal membrane targeting signal comprising a transmembrane domain and a positively charged loop and up-regulates expression of the manganese superoxide dismutase gene. J. Biol. Chem. 278, 6301-6306.

https://doi.org/10.1074/jbc.M210886200

Kaji, S., Murayama K., Nagata, I., Nagasaka, H., Takayanagi, M., Ohtake, A., Iwasa, H., Nishiyama, M., Okazaki, Y., Harashima, H., Eitoku, T., Yamamoto, M., Matsushita, H., Kitamoto, K., Sakata, S., Katayama, T., Sugimoto, S., Fujimoto, Y., Murakami, J., Kanzaki, S., Shiraki, K., 2009. Fluctuating liver functions in siblings with MPV17 mutations and possible improvement associated with dietary and pharmaceutical treatments targeting respiratory chain complex II. Mol. Genet. Metab. 97, 292-296. https://doi.org/10.1016/j.ymgme.2009.04.014

Karadimas, C.L., Vu, T.H., Holve, S.A., Chronopoulou, P., Quinzii, C., Johnsen, S.D., Kurth, J., Eggers, E., Palenzuela, L., Tanji, K., Bonilla, E., De Vivo, D.C., DiMauro, S., Hirano, M., 2006. Navajo neurohepatopathy is caused by a mutation in the MPV17 gene. Am. J. Hum. Genet. 79, 544-548. https://doi.org/10.1086/506913

Kim, J., Kang, E., Kim, Y., Kim, J.-M., Lee, B.H., Murayama, K., Kim, G.-H., Choi, I.H., Kim, K.M., Yoo, H.-W., 2016. MPV17 mutations in patients with hepatocerebral mitochondrial DNA depletion syndrome. Mol. Genet. Metab. Rep. 8, 74-76. https://doi.org/10.1016/j.ymgmr.2016.06.006

Lang, B.F., Gray, M.W., Burger, G., 1999. Mitochondrial genome evolution and the origin of eukaryotes Annu. Rev. Genet. 33, 351-397. https://doi.org/10.1146/annurev.genet.33.1.351

Löllgen, S., Weiher, H., 2015. The role of the Mpv17 protein mutations of which cause mitochondrial DNA depletion syndrome (MDDS): lessons from homologs in different species. Biol. Chem. 396, 13-25. https://doi.org/10.1515/hsz-2014-0198

McKiernan, P., Ball, S., Santra, S., Foster, K., Fratter, C., Poulton, J., Craig, K., McFarland, R., Rahman, S., Hargreaves, I., Gupte, G., Sharif, K., Taylor, R.W., 2016. Incidence of Primary

This article is protected by copyright. All rights reserved. 
Mitochondrial Disease in Children Younger Than 2 Years Presenting With Acute Liver Failure. J. Pediatr. Gastroenterol. Nutr. 63, 592-597. https://doi.org/10.1097/MPG.0000000000001345

Mendelsohn, B.A., Mehta, N., Hameed, B., Pekmezci, M., Packman, S., Ralph, J., 2014. Adult-Onset Fatal Neurohepatopathy in a Woman Caused by MPV17 Mutation. JIMD Rep. 13, 37-41. https://doi.org/10.1007/8904_2013_267

Merkle, A.N, Nascene, D.R., McKinney, A.M., 2012. MR imaging findings in the reticular formation in siblings with MPV17-related mitochondrial depletion syndrome. AJNR Am. J. Neuroradiol. 33,E34-35. https://doi.org/10.3174/ajnr.A2455

Navarro-Sastre, A., Martín-Hernández, E., Campos, Y., Quintana, E., Medina, E., de Las Heras, R.S., Llựh, M., Muñoz, A., del Hoyo, P., Martín, R., Gort, L., Briones, P., Ribes, A., 2008. Lethal hepatopathy and leukodystrophy caused by a novel mutation in MPV17 gene: description of an alternative MPV17 spliced form. Mol. Genet. Metab. 94, 234-239.

https://doi.org/10.1016/j.ymgme.2008.01.012

Nogueira, C., de Souza, C.F.M., Husny, A., Derks, T.G.J., Santorelli, F.M., Vilarinho, L., 2012. MPV17: fatal hepatocerebral presentation in a Brazilian infant. Mol. Genet. Metab. 107, 764. https://doi.org/10.1016/j.ymgme.2012.10.010

Parikh, S., Karaa,A., Goldstein, A., Ng, Y.S., Gorman, G., Feigenbaum, A., Christodoulou, J., Haas, R.,Tarnopolsky, M., Cohen, B.K., Dimmock, D., Feyma, T., Koenig, M.K., Mundy, H., Niyazov, D, Saneto, R.P., Wainwright, M.S., Wusthoff, C., McFarland, R., Scaglia, F., 2016. Solid organ transplantation in primary mitochondrial disease: Proceed with caution. Mol. Genet. Metab. 118, 178-184. https://doi.org/10.1016/j.ymgme.2016.04.009

Parini, R., Furlan, F., Notarangelo, L., Spinazzola, A., Uziel, G., Strisciuglio, P., Concolino, D., Corbetta, C, Nebbia, G., Menni, F., Rossi, G., Maggioni, M., Zeviani, M., 2009. Glucose metabolism and diet-based prevention of liver dysfunction in MPV17 mutant patients. J. Hepatol. 50, 215-221. https://doi.org/10.1016/j.jhep.2008.08.019

Piekutowska-Abramczuk, D., Pronicki, M., Strawa, K., Karkucińska-Więckowska, A., Szymańska-Dębińska, T., Fidziańska, A., Więckowski, M.R., Jurkiewicz, D., Ciara, E., Jankowska, I., Sykut-Cegielska, J., Krajewska-Walasek, M., Płoski, R., Pronicka, E., 2014. Novel c.191 C $>$ G (p.Pro64Arg) MPV17 mutation identified in two pairs of unrelated Polish siblings with mitochondrial hepatoencephalopathy. Clin. Genet. 85, 573-577. https://doi.org/10.1111/cge. 12228

Sarkhy, A.A., Al-Sunaid, A., Abdullah, A., AlFadhel, M., Eiyad, W., 2014. A novel MPV17 gene mutation in a Saudi infant causing fatal progressive liver failure. Ann. Saudi Med. 34, 175-178. https://doi.org/10.5144/0256-4947.2014.175

Spinazzola, A., 2011. Mitochondrial DNA mutations and depletion in pediatric medicine. Semin. Fetal. NeonatalMed. 16, 190-196. https://doi.org/10.1016/j.siny.2011.04.011

Spinazzola, A., Santer, R., Akman, O.H., Tsiakas, K., Schaefer, H., Ding, X., Karadimas, C.L., Shanske, S., Ganesh, J., Di Mauro, S., Zeviani, M., 2008. Hepatocerebral form of mitochondrial DNA depletion syndrome: novel MPV17 mutations. Arch. Neurol. 65, 11081113. https://doi.org/10.1001/archneur.65.8.1108

Spinazzela, A., Viscomi, C., Fernandez-Vizarra, E., Carrara, F., D’Adamo, P., Calvo, S., Marsano, R.M., Donnini, C., Weiher, H., Strisciuglio, P., Parini, R., Sarzi, E., Chan, A., DiMauro, S., Rötig, A., Gasparini, P., Ferrero, I., Mootha, V.K., Tiranti, V., Zeviani, M., 2006. MPV17 encodes an inner mitochondrial membrane protein and is mutated in infantile hepatic mitochondrial DNA depletion. Nat. Genet. 38, 570-575. https://doi.org/10.1038/ng1765

Uusimaa, J., Evans, J., Smith, C., Butterworth, A., Craig, K., Ashley, N., Liao, C., Carver, J., Diot, A., Macleod, L., Hargreaves, I., Al-Hussaini, A., Faqeih, E., Asery, A., Al Balwi, M., Eyaid, W., Al-Sunaid, A., Kelly, D., van Mourik, I., Ball, S., Jarvis, J., Mulay, A., Hadzic, N., Samyn, M., Baker, A., Rahman, S., Stewart, H., Morris, A.A., Seller, A., Fratter, C., Taylor, R.W., Poulton,

This article is protected by copyright. All rights reserved. 
J., 2014. Clinical, biochemical, cellular and molecular characterization of mitochondrial DNA depletion syndrome due to novel mutations in the MPV17 gene. Eur. J. Hum. Genet. EJHG 22, 184-191. https://doi.org/10.1038/ejhg.2013.112

Vilarinho, S., Choi, M., Jain, D., Malhotra, A., Kulkarni, S., Pashankar, D., Phatak, U., Patel, M., Bale, A., Mane, S., Lifton, R.P., Mistry, P.K., 2014. Individual exome analysis in diagnosis and management of paediatric liver failure of indeterminate aetiology. J. Hepatol. 61, 1056-1063. https://doi.org/10.1016/j.jhep.2014.06.038

Wong, L.-J.C., Brunetti-Pierri, N., Zhang, Q., Yazigi, N., Bove, K.E., Dahms, B.B., Puchowicz, M.A., Gonzalez-Gomez, I., Schmitt, E.S., Truong, C.K., Hoppel, C.L., Chou, P.-C., Wang, J., Baldwin, E.E., Adams, D., Leslie, N., Boles, R.G., Kerr, D.S., Craigen, W.J., 2007. Mutations in the MPV17 gene are responsible for rapidly progressive liver failure in infancy. Hepatol. Baltim. Md 46, 1218-1227. https://doi.org/10.1002/hep.21799

This article is protected by copyright. All rights reserved. 


\section{Figure legends}

Figure 1. The alignment of pathogenic variants on the $M P V 17$ gene.
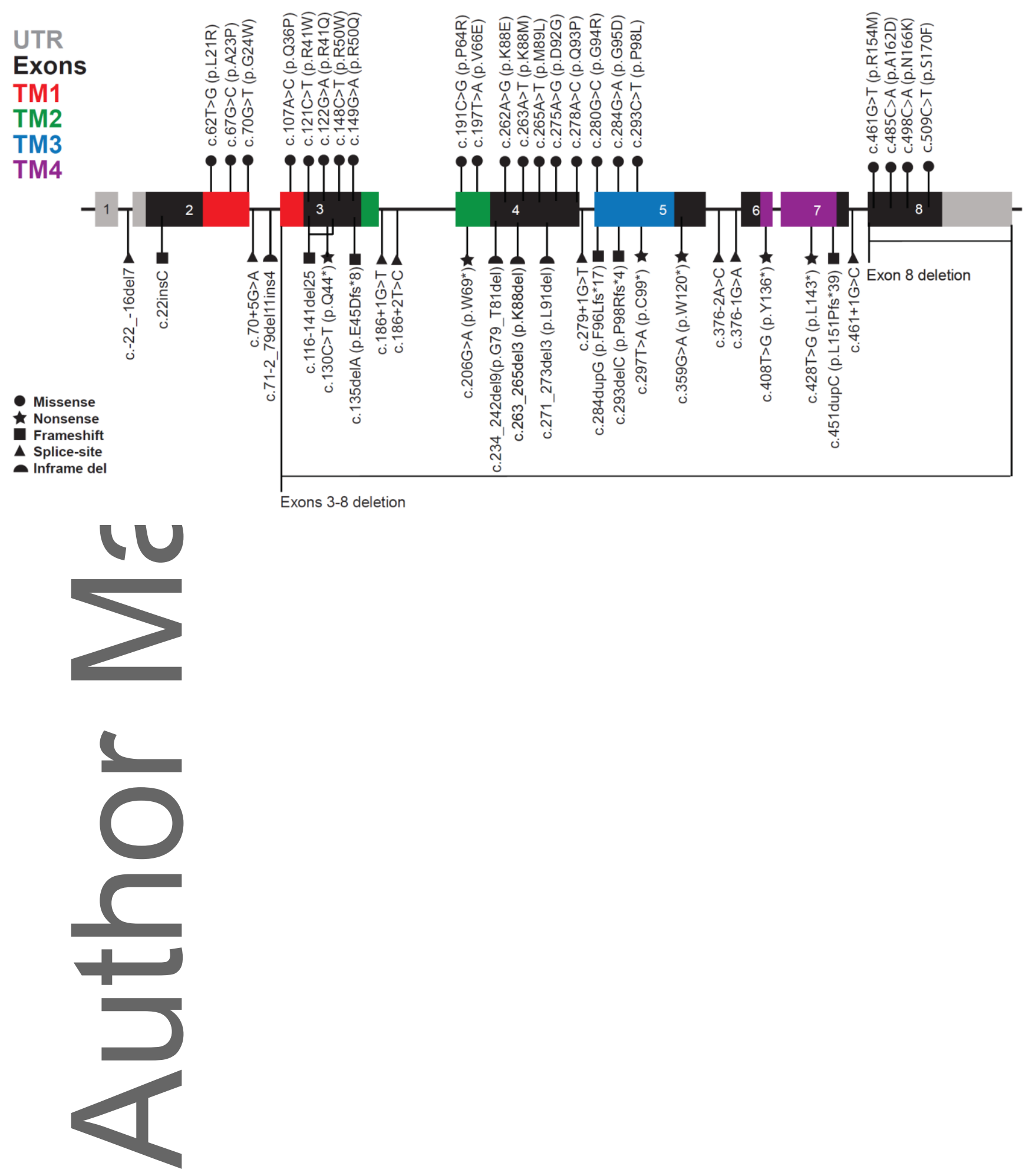

This article is protected by copyright. All rights reserved. 
Figure 2. The alignment of the missense pathogenic variants on the MPV17 protein.

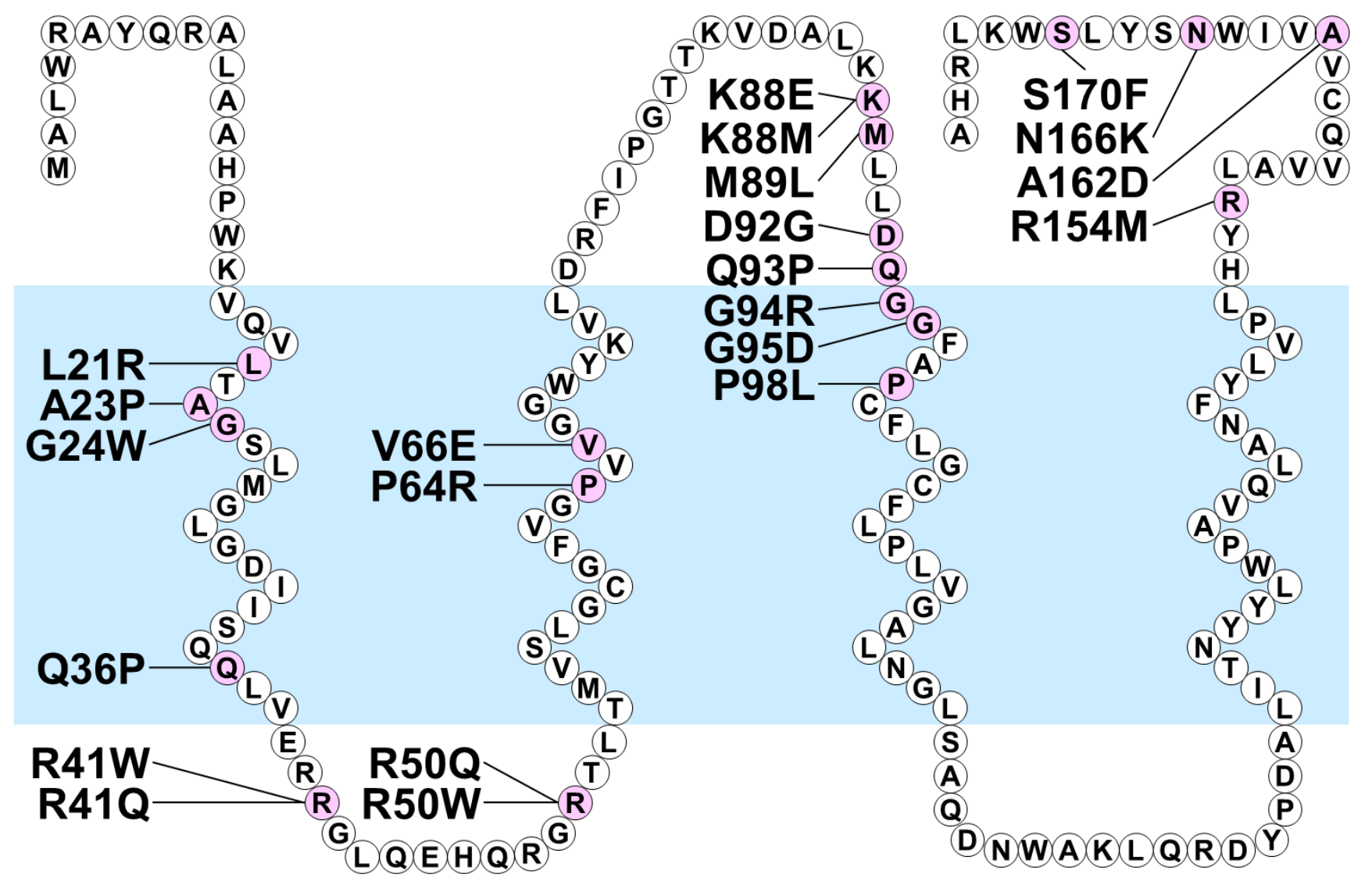

This article is protected by copyright. All rights reserved. 
Figure 3. Age of onset for MPV17-related mtDNA maintenance defect. The height of red columns represents the number of affected individuals with MPV17-related encephalohepatopathy at each age group. The height of blue columns represents the number of affected individuals with MPV17-related neuromyopathy.

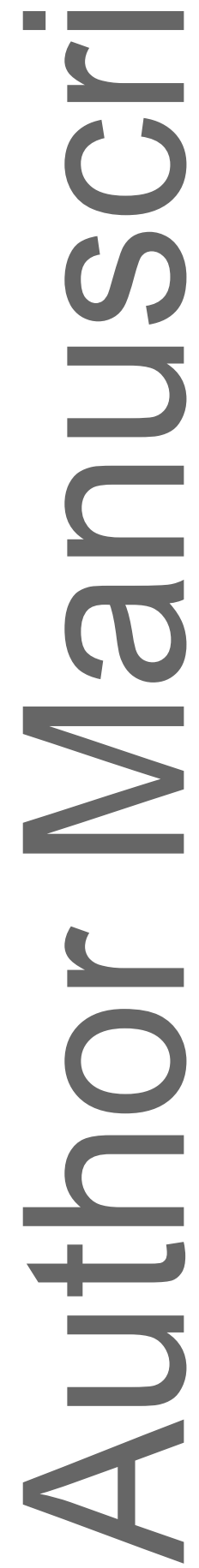

This article is protected by copyright. All rights reserved. 


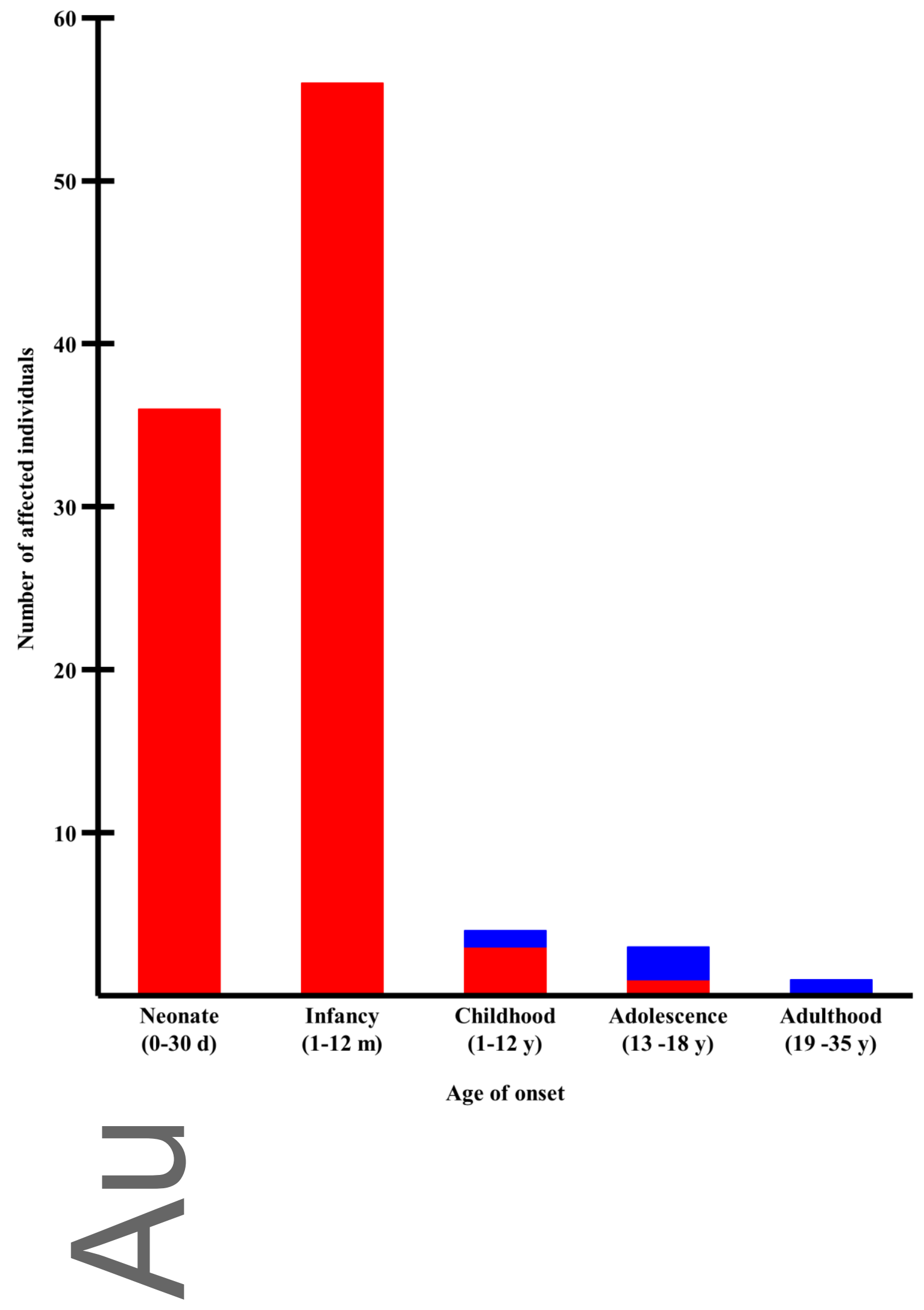

This article is protected by copyright. All rights reserved. 
Table 1. Pathogenic variants in MPV17 in previously reported and individuals described in this report.

\begin{tabular}{|c|c|c|c|c|c|c|}
\hline & $\begin{array}{l}\text { Previc } \\
\text { ( } n=73\end{array}$ & reported & This $r$ & $t(n=25)$ & Total & \\
\hline & Hom & Het & Hom & Het & Hom & Het \\
\hline $\begin{array}{l}\text { Missense } \\
\text { mutations }\end{array}$ & & & & & & \\
\hline c.62T>G (p.L21R) & 2 & 0 & 1 & 0 & 3 & 0 \\
\hline c.67G >C (p.A23P) & 0 & 1 & 0 & 0 & 0 & 1 \\
\hline c.70G>T (p.G24W) & 0 & 1 & 0 & 0 & 0 & 1 \\
\hline c.107A>C (p.Q36P) & 1 & 0 & 0 & 0 & 1 & 0 \\
\hline c.121C>T (p.R41W) & 2 & 0 & 0 & 0 & 2 & 0 \\
\hline c.122G>A (p.R41Q) & 2 & $O A$ & 0 & 0 & 2 & 0 \\
\hline$c>T(p . R 50 W)$ & 2 & 1 & 1 & 1 & 3 & 2 \\
\hline$i>A(p . R 50 Q)$ & 11 & 0 & 0 & 0 & 11 & 0 \\
\hline$>G(p . P 64 R)$ & 4 & 1 & 0 & 0 & 4 & 1 \\
\hline 10 c.197T>A (p.V66E) & 0 & 1 & 0 & 0 & 0 & 1 \\
\hline c.262A>G (p.K88E) & 1 & 0 & 0 & 0 & 1 & 0 \\
\hline $\begin{array}{l}A>T \\
M)^{*}\end{array}$ & 0 & 1 & 0 & 0 & 0 & 1 \\
\hline c. $265 \mathrm{~A}>\mathrm{T}(\mathrm{p} . \mathrm{M} 89 \mathrm{~L})^{*}$ & 0 & 1 & 0 & 0 & 0 & 1 \\
\hline c.275A >G (p.D92G) & 0 & 0 & 0 & 1 & 0 & 1 \\
\hline c.278A>C (p.Q93P) & 9 & 0 & 3 & 0 & 12 & 0 \\
\hline c.280G $>$ C (p.G94R) & 0 & 2 & 0 & 0 & 0 & 2 \\
\hline c.284G>A (p.G95D) & 0 & 0 & 1 & 0 & 1 & 0 \\
\hline c.293C>T (p.P98L) & 2 & 5 & 0 & 5 & 2 & 10 \\
\hline
\end{tabular}

This article is protected by copyright. All rights reserved. 


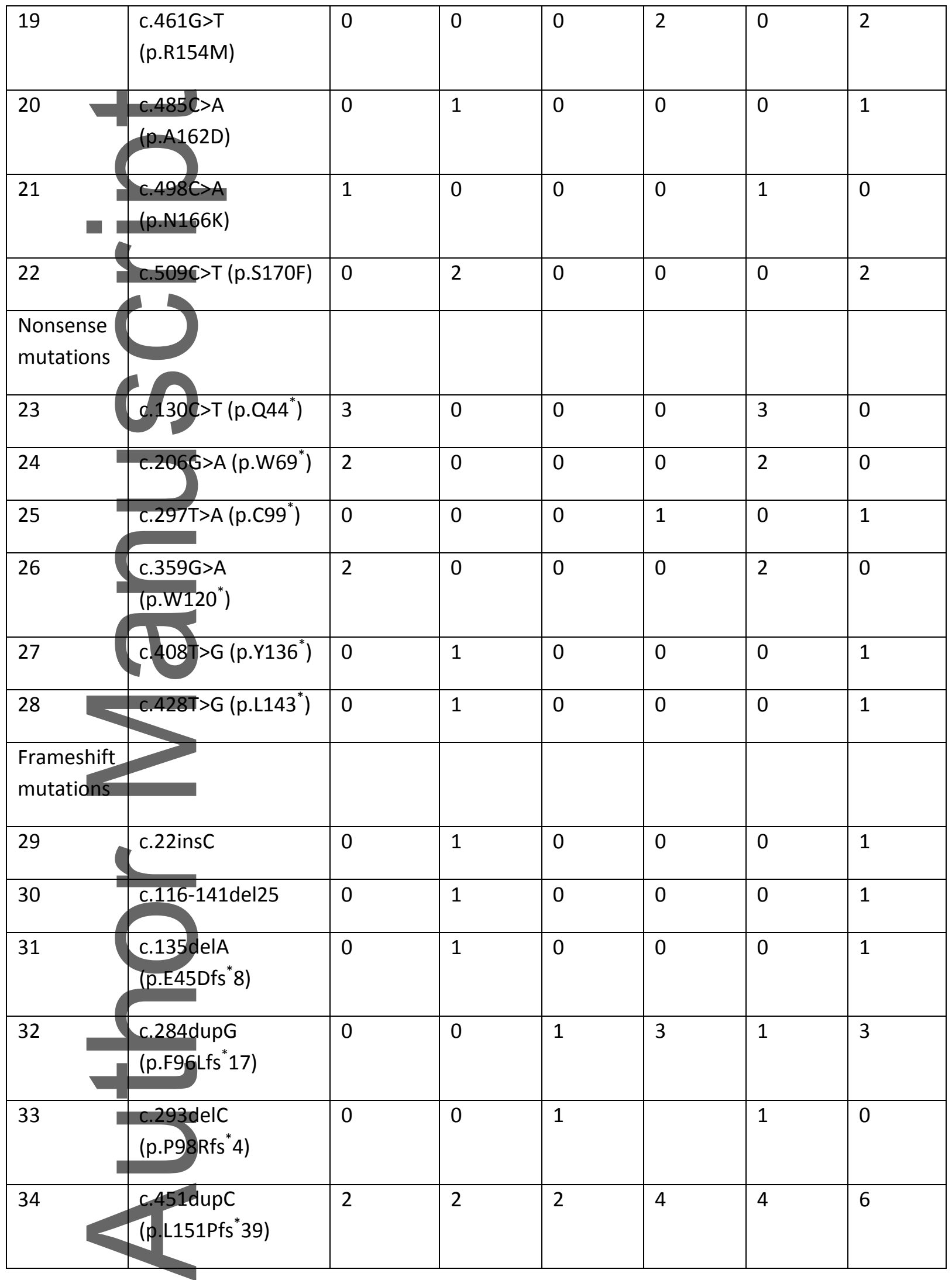

This article is protected by copyright. All rights reserved. 


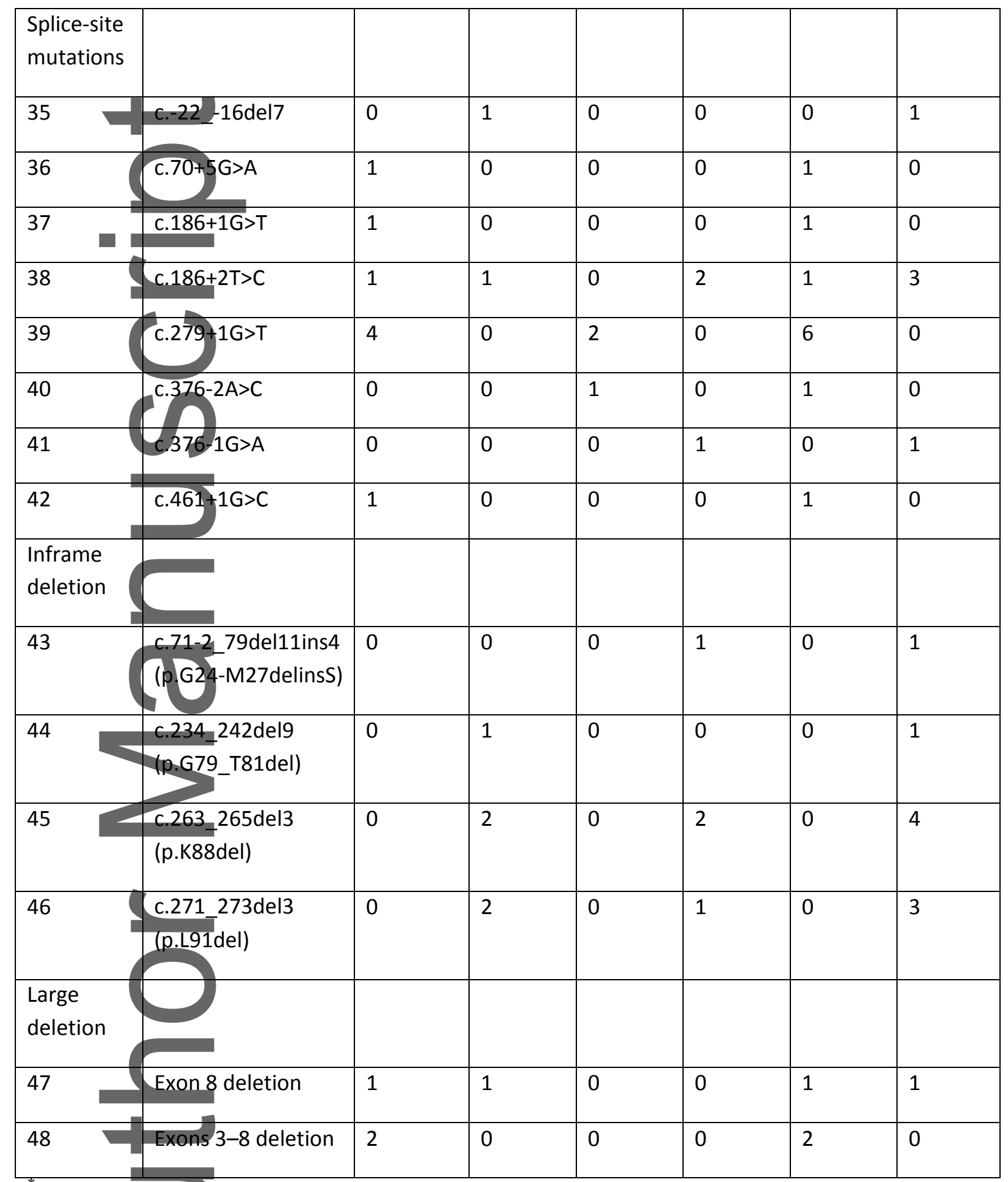

"c.263A $>\mathrm{T}$ (p.K88M) \& c.265A $>$ T (p.M89L) in cis

This article is protected by copyright. All rights reserved. 
Table 2. Clinical and biochemical features of individuals with MPV17-related encephalohepatopathic mtDNA maintenance defect.

\begin{tabular}{|c|c|c|c|}
\hline & Previously reported & This report & Total \\
\hline Number of individuals & 71 & 25 & 96 \\
\hline Number of & 56 & 23 & 79 \\
\hline Male:Fem & $39: 31$ & $11: 14$ & $50: 45$ \\
\hline Presentati & Neonate - $18 y$ & Neonate - $8 \mathrm{~m}$ & Neonate - 18 y \\
\hline Outcome & Alive 16. Dead 55 & Alive 5. Dead 20 & Alive 21. Dead 75 \\
\hline Hepatic m & & & \\
\hline Liver dysfun & $71 / 71$ (100\%) & $25 / 25(100 \%)$ & 96/96 (100\%) \\
\hline Liver failur & $65 / 71(92 \%)$ & $22 / 25(88 \%)$ & $87 / 96$ (91\%) \\
\hline Cholestasis & $46 / 71(65 \%)$ & $24 / 25$ (96\%) & 70/96 (73\%) \\
\hline Hepatomegaly & $38 / 71(54 \%)$ & $22 / 25(88 \%)$ & $60 / 96$ (63\%) \\
\hline Steatosis & $37 / 71(52 \%)$ & $12 / 25(48 \%)$ & 49/96 (51\%) \\
\hline Liver cirrh & $14 / 71(20 \%)$ & $6 / 25(24 \%)$ & $20 / 96$ (21\%) \\
\hline Hepatocellutare & $3 / 71(4 \%)$ & $0 / 25(0 \%)$ & $3 / 96(3 \%)$ \\
\hline \multicolumn{4}{|l|}{$\begin{array}{l}\text { Neurologic } \\
\text { manifestations }\end{array}$} \\
\hline Developmentald & $54 / 68$ (79\%) & $21 / 23(91 \%)$ & $75 / 91(82 \%)$ \\
\hline Hypotonia & $48 / 68$ (71\%) & $19 / 23(83 \%)$ & $67 / 91$ (74\%) \\
\hline Microceph & $9 / 68(13 \%)$ & $12 / 23(52 \%)$ & $21 / 91(23 \%)$ \\
\hline Peripheral neuropathy & $16 / 68(24 \%)$ & $1 / 23(4 \%)$ & $17 / 91(19 \%)$ \\
\hline Seizures & $6 / 68(9 \%)$ & $3 / 23(13 \%)$ & 9/91 (10\%) \\
\hline Dystonia & $2 / 68(3 \%)$ & $2 / 23(9 \%)$ & $4 / 91(4 \%)$ \\
\hline Ataxia & $3 / 68(4 \%)$ & $0 / 23(0 \%)$ & $3 / 91(3 \%)$ \\
\hline
\end{tabular}

This article is protected by copyright. All rights reserved. 


\begin{tabular}{|c|c|c|c|}
\hline $\begin{array}{l}\text { Neuroimaging } \\
\text { abnormalities }\end{array}$ & & & \\
\hline White matter & $21 / 54(39 \%)$ & $6 / 17(35 \%)$ & $27 / 71(38 \%)$ \\
\hline $\begin{array}{l}\text { Brainstem signal } \\
\text { abnormalities }\end{array}$ & $5 / 54(9 \%)$ & $1 / 17(6 \%)$ & $6 / 71(8 \%)$ \\
\hline $\begin{array}{l}\text { Basal ganglia signal } \\
\text { abnormalities }\end{array}$ & $3 / 54(6 \%)$ & $3 / 17(18 \%)$ & $6 / 71(8 \%)$ \\
\hline $\begin{array}{l}\text { Ophthalmc } \\
\text { manifestat }\end{array}$ & & & \\
\hline Retinopath & $6 / 68(9 \%)$ & $1 / 23(4 \%)$ & $7 / 91(8 \%)$ \\
\hline Nystagmu & $3 / 68(4 \%)$ & $3 / 23(13 \%)$ & $6 / 91(7 \%)$ \\
\hline $\begin{array}{l}\text { Corneal } \\
\text { anesthesial }\end{array}$ & $4 / 68(6 \%)$ & $0 / 23(0 \%)$ & $4 / 91(4 \%)$ \\
\hline $\begin{array}{l}\text { Gastroint } \\
\text { manifesta }\end{array}$ & & & \\
\hline Failure to & $61 / 68(90 \%)$ & $21 / 23(91 \%)$ & $82 / 91(90 \%)$ \\
\hline $\begin{array}{l}\text { Gastrointestinal } \\
\text { dysmotility }\end{array}$ & $15 / 68(22 \%)$ & $15 / 23(65 \%)$ & $30 / 91(33 \%)$ \\
\hline Feeding difficulties & 9/68 (13\%) & $19 / 23(83 \%)$ & $28 / 91(31 \%)$ \\
\hline \multicolumn{4}{|l|}{ Renal manifestations } \\
\hline Renal tubul & $7 / 68(10 \%)$ & $2 / 23(9 \%)$ & 9/91 (10\%) \\
\hline Nephrocalcinosis & $4 / 68(6 \%)$ & $3 / 23(13 \%)$ & $7 / 91(8 \%)$ \\
\hline \multicolumn{4}{|l|}{$\begin{array}{l}\text { Endocrine } \\
\text { manifestations }\end{array}$} \\
\hline Hypoparathyroidism & $3 / 68(4 \%)$ & $1 / 23(4 \%)$ & $4 / 91(4 \%)$ \\
\hline $\begin{array}{l}\text { Metabolic } \\
\text { abnormalities }\end{array}$ & & & \\
\hline
\end{tabular}

This article is protected by copyright. All rights reserved. 


\begin{tabular}{|l|l|l|l|}
\hline Lactic acidemia & $52 / 68(76 \%)$ & $20 / 23(87 \%)$ & $72 / 91(79 \%)$ \\
\hline Hypoglycemia & $38 / 68(56 \%)$ & $17 / 23(74 \%)$ & $55 / 91(60 \%)$ \\
\hline ETC complexes activity & & & \\
\hline Low Cl & $22 / 27(81 \%)$ & $6 / 8(75 \%)$ & $28 / 35(80 \%)$ \\
\hline Low ClI & $8 / 27(30 \%)$ & $0 / 8(0 \%)$ & $8 / 35(23 \%)$ \\
\hline Low CIII & $15 / 27(56 \%)$ & $5 / 8(63 \%)$ & $20 / 35(57 \%)$ \\
\hline Low CIV & $21 / 27(78 \%)$ & $3 / 8(38 \%)$ & $1-40 \%(n=47)$ \\
\hline MtDNA content jin liver & $3-40 \%(n=37)$ & $1-20 \%(n=10)$ & $8-100 \%(n=18)$ \\
\hline $\begin{array}{l}\text { MtDNA content in } \\
\text { muscle }\end{array}$ & $8-100 \%(n=18)$ & NA & \\
\hline
\end{tabular}

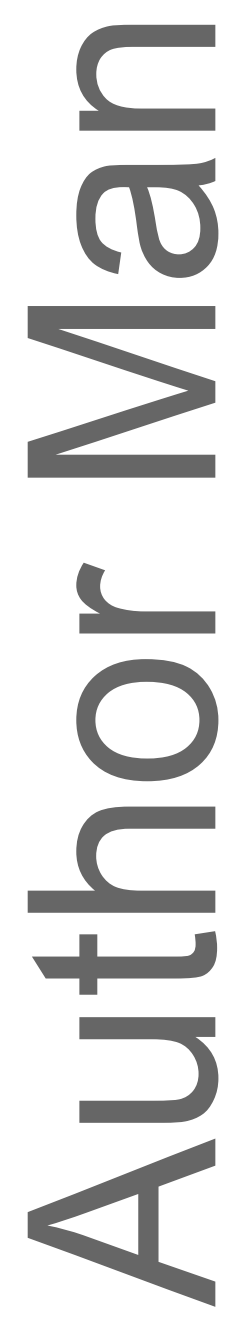

This article is protected by copyright. All rights reserved. 